\title{
Stereospecific Anionic Polymerization of Novel $\alpha$-Substituted Acrylates Bearing Aromatic Heterocycles
}

\author{
Shigeki Habaue, Hideo Baraki, Tomoyuki Shibagaki, and Yoshio Okamoto ${ }^{\dagger}$ \\ Department of Applied Chemistry, Graduate School of Engineering, \\ Nagoya University, Furo-cho, Chikusa-ku, Nagoya 464-8603, Japan
}

(Received July 5, 1999)

KEY WORDS Stereospecific Polymerization / Anionic Polymerization / $\alpha$-Substituted Acrylate / Aromatic Heterocycle / Isotactic Polymer / Lithium Reagent /

Development of methods for stereoregular arrangement of various functional groups along a main-chain may be particularly important for designing novel functional polymers. In anionic polymerization of vinyl monomers, the tacticity of polymers is often greatly affected by polymerization conditions such as polarity of solvents and initiators. Therefore, the introduction of a polar functional group to a vinyl monomer that can interact with a counter-cation greatly influences stereoregularity, and design of functional groups in vinyl monomer provides a useful methodology for the stereocontrol in anionic polymerization. The anionic polymerization of a variety of $\alpha$-substituted acrylates having alkoxymethyl $^{1}$ and aminomethyl ${ }^{2}$ groups on their $\alpha$-position with lithium reagents gave highly isotactic polymers regardless of the polarity of solvents, while radical polymerization was unsuccessful or resulted in generation of atactic polymers. Strong intra- and intermolecular coordination of the polar substituents of the growing polymer chain and monomers to the counter-cation $\left(\mathrm{Li}^{+}\right)$, especially, a stable six-membered chelation of intermediate lithium enolate, should be the main factor in controlling stereochemistry.

$$
[\underbrace{C_{O R}^{\prime}}_{X=O, N, S}
$$

We recently reported that ethyl $\alpha$-(2-thienylmethyl) acrylate (1) provides a polymer with a high isotacticity regardless of the polarity of solvents under the anionic conditions. ${ }^{3}$ Here, the stereospecific anionic polymerization developed for $\alpha$-(alkoxymethyl)acrylates ${ }^{1}$ and $\alpha$ (aminomethyl)acrylates ${ }^{2}$ is expanded to novel $\alpha$-substituted acrylates having various aromatic heterocycles at the $\alpha$-position. Further investigation was made on the anionic polymerization of $\mathbf{1}$ and effects of other aromatic heterocycles on the reactivity and stereoregularity in the anionic polymerization using three novel monomers, ethyl $\alpha$-(2-thianaphthenylmethyl)acrylate (2), ethyl $\alpha$-(2furylmethyl)acrylate (3), and ethyl $\alpha$-(2-pyridylmethyl) acrylate (4).

\footnotetext{
${ }^{\dagger}$ To whom all correspondence should be addressed.
}

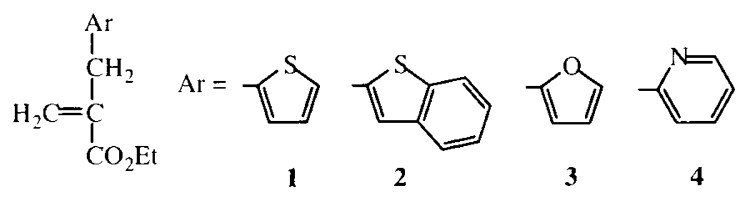

The radical and anionic polymerizations of $\alpha$-(alkyl) acrylates $^{4-6}$ including $\alpha$-(benzyl)acrylates ${ }^{7}$ have been conducted but no data are available about the polymerization of $\alpha$-substituted acrylate having an aromatic heterocycle on its $\alpha$-position so far as we know. Stereoregular polymers having a variety of aromatic heterocycles in the side chain are attractive as reactive polymers, polymeric ligands, etc. Although thiophene and poly(thiophene) derivatives have received considerable attention for electronic conductivities in the partially oxidized state, few data are available about the stereocontrolled polymers with pendant thiophene groups. ${ }^{8}$

\section{EXPERIMENTAL}

Solvents and reagents were purified or prepared as reported previously. ${ }^{1-3}$ Monomers $(2-4)$ were synthesized from ethyl $\alpha$-(bromomethyl)acrylate ${ }^{9}$ according to the procedure previously reported for $1 .^{3}$

Ethyl $\alpha$-(2-thianaphthenylmethyl)acrylate $\quad(\mathbf{2}): \mathrm{bp}$ $118.0-120.0^{\circ} \mathrm{C} / 0.50 \mathrm{mmHg} ;{ }^{1} \mathrm{H}$ NMR $\left(400 \mathrm{MHz}, \mathrm{CDCl}_{3}\right)$ $\delta 1.29\left(\mathrm{t}, 3 \mathrm{H}, J=7.2 \mathrm{~Hz}, \mathrm{CH}_{3}\right), 3.91\left(\mathrm{~s}, 2 \mathrm{H},-\mathrm{CH}_{2}\right), 4.23(\mathrm{q}$, $\left.2 \mathrm{H}, J=7.2 \mathrm{~Hz}, \mathrm{OCH}_{2}\right), 5.68(\mathrm{~m}, 1 \mathrm{H}$, vinyl $), 6.31(\mathrm{~m}, 1 \mathrm{H}$, vinyl), $7.00-7.80\left(\mathrm{~m}, 5 \mathrm{H}\right.$, aromatic) ; IR (neat, $\mathrm{cm}^{-1}$ ) 2981, 1713, 1632, 1458, 1436, 1300, 1254, 1181, 1026, $951 ; \mathrm{MS}(\mathrm{FAB}) \mathrm{m} / z 246\left(\mathrm{M}^{+}\right)$.

Ethyl $\alpha$-(2-furylmethyl)acrylate $(3):{ }^{1} \mathrm{H}$ NMR $(400$ $\left.\mathrm{MHz} \mathrm{CDCl}_{3}\right) \delta 1.29\left(\mathrm{t}, 3 \mathrm{H}, J=7.2 \mathrm{~Hz}, \mathrm{CH}_{3}\right), 3.66(\mathrm{~s}, 2 \mathrm{H}$, $\left.-\mathrm{CH}_{2}\right), 4.21\left(\mathrm{q}, 2 \mathrm{H}, J=7.2 \mathrm{~Hz}, \mathrm{OCH}_{2}\right), 5.54(\mathrm{~d}, 1 \mathrm{H}, J=$ $1.2 \mathrm{~Hz}$, vinyl), $6.08(\mathrm{~m}, 1 \mathrm{H}$, furan), $6.26(\mathrm{~d}, 1 \mathrm{H}, J=1.2$ $\mathrm{Hz}$, vinyl), $6.30(\mathrm{~m}, 1 \mathrm{H}$, furan), $7.33(\mathrm{~m}, 1 \mathrm{H}$, furan) ; IR (neat, $\mathrm{cm}^{-1}$ ) 2982, 1718, 1635, 1506, 1302, 1284, 1256, 1182, 1135, 1011. Anal. Calcd for $\mathrm{C}_{10} \mathrm{H}_{12} \mathrm{O}_{3}$ : C, 66.65\%; $\mathrm{H}, 6.71 \%$. Found : C, $66.63 \% ; \mathrm{H}, 6.69 \%$.

Ethyl $\alpha$-(2-pyridylmethyl)acrylate (4) : bp $68.0-71.0$ ${ }^{\circ} \mathrm{C} / 0.25 \mathrm{mmHg} ;{ }^{1} \mathrm{H} \mathrm{NMR}\left(400 \mathrm{MHz}, \mathrm{CDCl}_{3}\right) \delta 1.24(\mathrm{t}, 3 \mathrm{H}$, $\left.J=7.2 \mathrm{~Hz}, \mathrm{CH}_{3}\right), 3.83\left(\mathrm{~s}, 2 \mathrm{H},-\mathrm{CH}_{2}\right), 4.17$ (q, $2 \mathrm{H}, J=7.2$ $\left.\mathrm{Hz}, \mathrm{OCH}_{2}\right), 5.61(\mathrm{~s}, 1 \mathrm{H}$, vinyl), $6.32(\mathrm{~s}, 1 \mathrm{H}$, vinyl), 7.108.60 (m, 5H, aromatic) ; IR (neat, $\mathrm{cm}^{-1}$ ) 2982, 1715, 1633, 1591, 1475, 1435, 1302, 1194, 1027, 762. Anal. Calcd for $\mathrm{C}_{11} \mathrm{H}_{13} \mathrm{NO}_{2}: \mathrm{C}, 69.09 \% ; \mathrm{H}, 6.85 \% ; \mathrm{N}, 7.32 \%$. Found : $\mathrm{C}$, $68.97 \%$; H, $6.98 \%$; N, 7.48\%. 
Table I. Anionic polymerizetion of $1-4$ at $-78^{\circ} \mathrm{C}^{\mathrm{a}}$

\begin{tabular}{|c|c|c|c|c|c|c|c|}
\hline Entry & Monomer & Initiator & Solvent & $\frac{\text { Time }}{\mathrm{h}}$ & $\frac{\text { Yield }^{\mathrm{b}}}{\%}$ & $\frac{M_{n}{ }^{\mathrm{c}}}{\times 10^{3}}$ & $M_{w} / M_{n}{ }^{\mathrm{c}}$ \\
\hline $1^{d}$ & 1 & $n-\mathrm{BuLi}$ & Toluene & 15 & 78 & 6.1 & 48 \\
\hline 2 & & $c \mathrm{HexMgBr}$ & Toluene & 48 & 2 & 4.7 & 8.8 \\
\hline 3 & & $c$ HexMgBr-TMEDA & Toluene & 20 & $97^{\mathrm{e}}$ & $9.0^{\mathrm{f}}$ & $84^{f}$ \\
\hline 4 & & Li Piperidide & Toluene & 20 & 76 & 8.6 & 110 \\
\hline 5 & 2 & $n$-BuLi & Toluene & 22 & 60 & 8.8 & 24 \\
\hline 6 & & $c$ HexMgBr-TMEDA & Toluene & 22 & 95 & 5.5 & 4.9 \\
\hline 7 & & $\mathrm{Ph}_{2} \mathrm{NLi} \mathrm{TMEDA}$ & Toluene & 22 & 89 & 4.9 & 1.2 \\
\hline 8 & & $n-\mathrm{BuLi}$ & $\mathrm{THF}$ & 22 & $>99$ & 8.5 & 1.6 \\
\hline 9 & $\mathbf{3}$ & $n-\mathrm{BuLi}$ & Toluene & 20 & 89 & 20 & 21 \\
\hline 10 & & $\mathrm{Ph}_{2} \mathrm{NLi}^{-\mathrm{TMEDA}}$ & Toluene & 20 & 78 & 7.4 & 1.1 \\
\hline 11 & & $n-\mathrm{BuLi}$ & THF & 20 & 87 & 15 & 2.1 \\
\hline 12 & 4 & $n-\mathrm{BuLi}$ & Toluene & 48 & $8^{\mathrm{g}}$ & $2.1^{\mathrm{h}}$ & - \\
\hline 13 & & $n-\mathrm{BuLi}$ & Toluene & 118 & $22^{\mathrm{g}}$ & $2.9^{h}$ & - \\
\hline 14 & & $\mathrm{Ph}_{2} \mathrm{NLi}$-TMEDA & Toluene & 48 & $12^{\mathrm{g}}$ & $2.3^{\mathrm{h}}$ & - \\
\hline 15 & & $n$-BuLi & THF & 48 & $10^{\mathrm{g}}$ & $2.5^{\mathrm{h}}$ & - \\
\hline
\end{tabular}

${ }^{a}$ Anionic polymerization : [monomer] / [initiator] $=20 .{ }^{b} \mathrm{MeOH}$ insoluble part. ${ }^{\mathrm{c}}$ Determined by SEC (polystyrene standard, eluent : $\left.\mathrm{CHCl}_{3}\right)$. ${ }^{\mathrm{d}} \mathrm{Ref} 3 .{ }^{\mathrm{e}} \mathrm{Partially}$ insoluble in $\mathrm{CHCl}_{3}\left(\mathrm{CHCl}_{3}\right.$ soluble part: $\left.80 \%\right) .{ }^{\mathrm{f}} \mathrm{CHCl}_{3}$ soluble part. ${ }^{\mathrm{g}} \mathrm{Hexane}$ insoluble part. ${ }^{\mathrm{h}}$ Eluent : THF, peak-top value.

Polymerization was carried out in the same way as reported. ${ }^{1-3}$

${ }^{1} \mathrm{H}$ and ${ }^{13} \mathrm{C}$ NMR spectra were measured on a Varian Gemini-2000 (400 MHz for $\left.{ }^{1} \mathrm{H}\right)$ or UNITY-INOVA (500 $\mathrm{MHz}$ for ${ }^{1} \mathrm{H}$ ) spectrometer in $\mathrm{CDCl}_{3}$ with tetramethylsilane as the internal standard. Infrared (IR) spectra were recorded on a JASCO FT/IR-550 spectrometer. Mass spectra were taken on a JEOL LMS-AX505HA mass spectrometer. DSC (Differential Scanning Calorimetry) measurement was carried out with a Seiko SSC -5200 equipped with a DSC-220 apparatus (at a heating rate of $\left.5^{\circ} \mathrm{C} \mathrm{min}^{-1}\right)$. Size exclusion chromatographic analysis (SEC) was performed on a JASCO 880-PU chromatograph equipped with a JASCO RI-930 refractive index detector using two commercial columns (TSK G $5000 \mathrm{H}$ and Shodex AC 802.5) connected in series for chloroform as an eluent, or Shodex System-21 SEC equipped with a Shodex UV-41 and Shodex RI-71S detectors using Shodex KF-830 and KF-806F SEC columns connected in series for tetrahydrofuran (THF) as an eluent. Calibration was performed using standard polystyrenes.

\section{RESULTS AND DISCUSSION}

The anionic polymerization of $\mathbf{1}$ using lithium reagents proceeds in a good yield, although the radical polymerization with $(i \text {-PrOCO})_{2}$ in toluene at $30^{\circ} \mathrm{C}$ gives no polymer. ${ }^{3}$ The polymers anionically obtained with $n$ $\mathrm{BuLi}$ were highly isotactic regardless of the polarity of solvents, toluene and THF. Further investigations on the anionic and radical polymerizations of $1-4$ were carried out. The radical polymerization of new monomers, 2-4, using $(i \text {-PrOCO})_{2}$ in toluene at $30^{\circ} \mathrm{C}$ resulted in poor or no yields $(<4 \%$ : hexane insoluble part) similarly to that for 1 . The results of anionic polymerization are listed in Table I, together with previous data on the anionic polymerization of $\mathbf{1}$ with $n$-BuLi in toluene (entry 1).

The acrylate having 2-thianaphthenylmethyl group on the $\alpha$-position (2) afforded a polymer using lithium reagents, $n-\mathrm{BuLi}$ and the complex of $\mathrm{Ph}_{2} \mathrm{NLi}$ with $N, N, N^{\prime}$, $N^{\prime}$-tetramethylethylenediamine (TMEDA), in good yields (entries 5, 7, and 8). Although the Grignard reagent, cyclohexylmagnesium bromide ( $c$ HexMgBr), gave a methanol insoluble polymer in a poor yield (entry 2), the polymerization of 1 and 2 using its complex with TMEDA proceeded in $97 \%$ and $95 \%$ yields, respectively (entries 3 and 6). Some polymers showed large polydispersity due to multi-modal peak distribution in SEC analysis, while the complex of lithium reagent with TMEDA effectively controlled a molecular weight distribution (entries 7, 10 and $M_{w} / M_{n}=1.3$ for poly $(\mathbf{1})^{3}$ ).

The ${ }^{13} \mathrm{C}$ NMR spectra of the carbonyl carbon of poly $(\mathbf{1}) \mathrm{s}$ and poly $(2)$ s are demonstrated in Figure 1. A sharp singlet is observed for poly(1) obtained with lithium piperidide (entry 2) (Figure 1a), indicating that a highly isotactic polymer is produced similarly to the polymerization with $n-\mathrm{BuLi}^{3}{ }^{3}$ However, the spectral pattern of the polymer prepared by $c \mathrm{HexMgBr}-\mathrm{TMEDA}$ is quite different from those of the polymer with high isotacticity produced by lithium piperidide and obtained using the complex of $N, N^{\prime}$-diphenylethylenediamine monolithium amide (DPEDALi) with TMEDA $^{3}$ (Figure 1b). Therefore, in addition to the basic diamine ligand, which should prevent the coordination of polar substituents of the growing polymer and monomer to the counter-cation, a counter-cation $\left(\mathrm{MgBr}^{+}\right)$may greatly affect the stereoregularity of the polymer. A sharp singlet is also observed for poly $(2)$ obtained with $n-\mathrm{BuLi}$ in toluene (entry 5) (Figure 1c), indicating that a highly isotactic polymer must be provided. In contrast to the polymerization of $\mathbf{1}, \operatorname{poly}(\mathbf{2})$ prepared in THF shows a much lower stereoregularity than that of $\operatorname{poly}(2)$ obtained in toluene (Figure 1d), although it appears to be still rich in isotacticity. The bulkiness and coordination ability of the polar substituents, thiophene and thianaphthene, of the growing polymer and monomers to the counter-cation $\left(\mathrm{Li}^{+}\right)$must greatly affect stereocontrol in the anionic polymerization.

The anionic polymerization of $\mathbf{3}$ with lithium reagents gave polymers in good yields (entries $9-11$ ). The ${ }^{1} \mathrm{H}$ NMR spectrum of the polymer obtained using $n-\mathrm{BuLi}$ in toluene is depicted in Figure 2. The spectral pattern is simple and each peak is assigned to a vinyl polymer corresponding to poly $(3)$. The spectral pattern of the main 


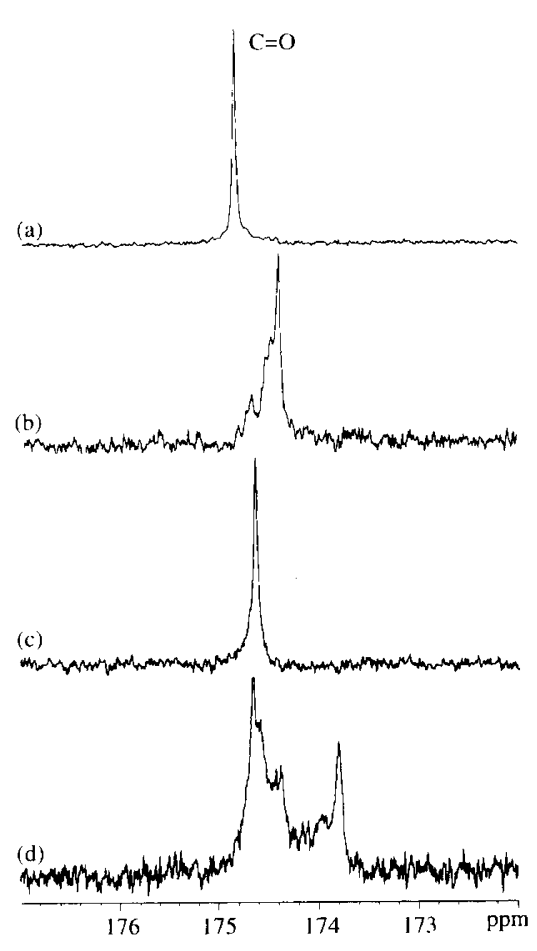

Figure 1. $125 \mathrm{MHz}{ }^{13} \mathrm{C}$ NMR spectra of the carbonyl carbon in poly(1)s obtained with lithium piperidide in toluene (entry 4) (a), $c$ HexMgBr-TMEDA (entry 3) (b), poly (2)s obtained with $n$-BuLi in toluene (entry 5) (c) and in THF (entry 8$)(\mathrm{d})\left(\mathrm{CDCl}_{3}, 60^{\circ} \mathrm{C}\right)$.

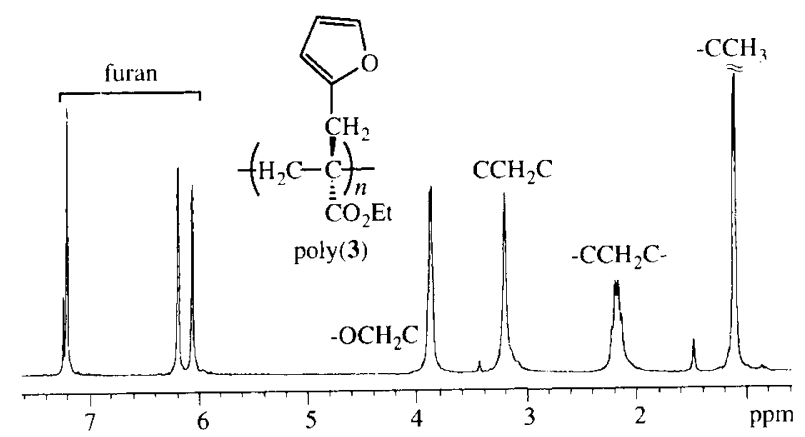

Figure 2. $500 \mathrm{MHz}^{1} \mathrm{H}$ NMR spectrum of poly(3) (entry 9) obtained with $n$-BuLi in toluene $\left(\mathrm{CDCl}_{3}, 60^{\circ} \mathrm{C}\right)$.

chain methylene protons around $2.2 \mathrm{ppm}$ shows a typical $\mathrm{AB}$ quartet with a coupling constant $15.0 \mathrm{~Hz}$ as shown in an expanded spectrum (Figure 3a). These observations indicate that a highly isotactic polymer is produced in the anionic polymerization of $\mathbf{3}$ in toluene similarly to the anionic polymerizations of $\mathbf{1}$ and $\mathbf{2}$.

Figure $4 \mathrm{a}$ shows the ${ }^{13} \mathrm{C}$ NMR spectrum of the carbonyl carbon of poly $(3)$ obtained with $n-\mathrm{BuLi}$ in toluene. A sharp singlet is observed, showing the polymer has high isotacticity. Interestingly, the polymers prepared in THF as well as using $\mathrm{Ph}_{2} \mathrm{NLi}$-TMEDA show different peak patterns, which seem to have some stereoregularity (Figures $4 \mathrm{~b}$ and $4 \mathrm{c}$ ). The spectral pattern of the main chain methylene protons in the ${ }^{1} \mathrm{H}$ NMR spectra of these polymers are quite different from that of the highly isotactic polymer and may be rich in syndiotacticity. The polymer obtained with $n$-BuLi in THF shows a small peaks for the isotactic diad (Figures $3 b$ and 3c). 2-

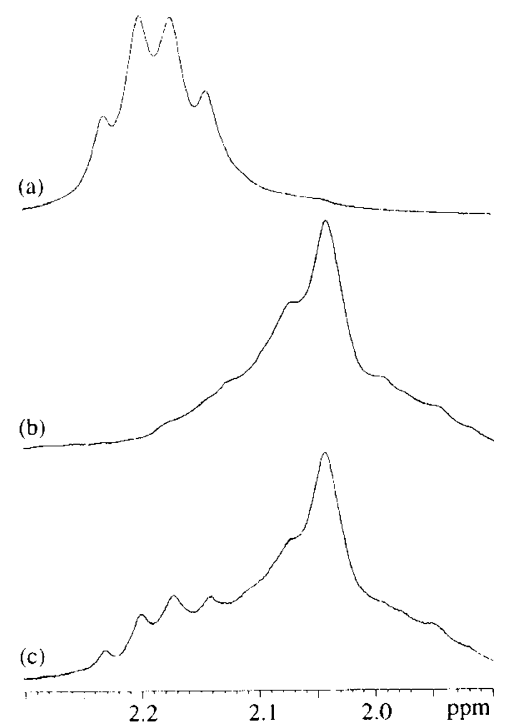

Figure 3. $500 \mathrm{MHz}{ }^{1} \mathrm{H}$ NMR spectra of the main chain methylene protons in poly $(3)$ s obtained with $n$-BuLi in toluene (entry 9 ) (a), $\mathrm{Ph}_{2} \mathrm{NLi}$-TMEDA (entry 10) (b) and $n$-BuLi in THF (entry 11) (c) $\left(\mathrm{CDCl}_{3}, 60^{\circ} \mathrm{C}\right)$.

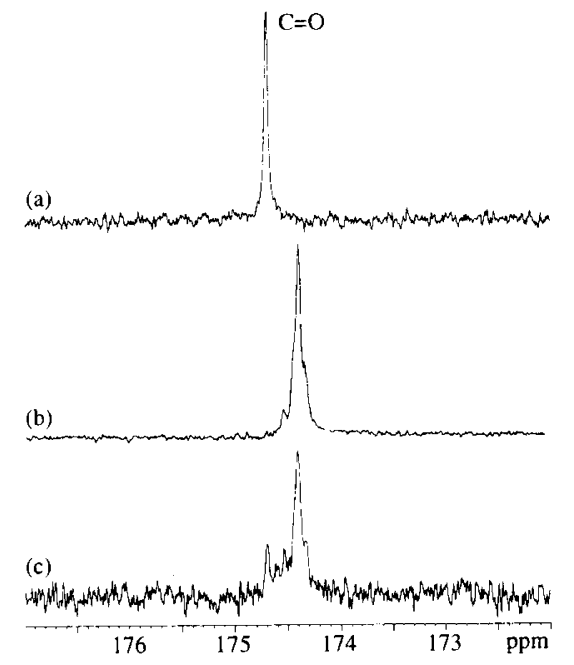

Figure 4. $125 \mathrm{MHz}^{13} \mathrm{C}$ NMR spectra of the carbonyl carbon in poly(3)s obtained with $n$-BuLi in toluene (entry 9) (a), $\mathrm{Ph}_{2} \mathrm{NLi}-$ TMEDA (entry 10) (b) and $n$-BuLi in THF (entry 11) (c) $\left(\mathrm{CDCl}_{3}, 60\right.$ $\left.{ }^{\circ} \mathrm{C}\right)$.

Furylmethyl group may be unable to control stereoregularity in polar solvents, in marked contrast to $\alpha$-(alkoxymethyl)acrylates, ${ }^{1} \alpha$-(aminomethyl)acrylates ${ }^{2}$ and $\mathbf{1}$.

2-Pyridylmethyl group in monomer 4 may have stronger coordination ability toward counter-cations, while it should be bulkier than other $\alpha$-substituents of 1 $\mathbf{- 3}$ because of its six-membered ring system. These characteristic features were reflected in the polymerizability and stereoregulation of the obtained polymer. The polymerization with lithium reagents in toluene or THF resulted in low yields of a hexane-insoluble polymer with low number-average molecular weight $\left(M_{n}\right)$ (entries 12-15), ${ }^{10}$ probably due to the bulkiness of the $\alpha$ substituent similarly to the polymerization of $\alpha$ substituted acrylates reported previously. ${ }^{1,2,4,7}$

The ${ }^{1} \mathrm{H}$ NMR spectrum of the obtained polymer using $n$-BuLi in toluene (entry 12) is demonstrated in Figure 5. 


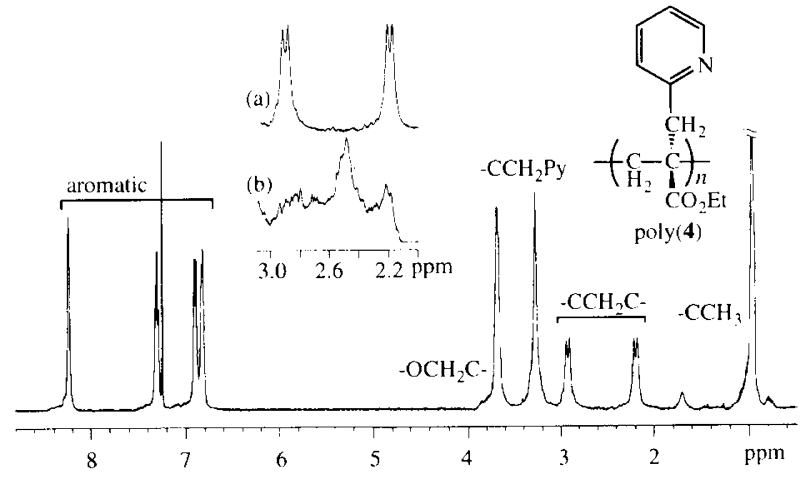

Figure 5. $400 \mathrm{MHz}{ }^{1} \mathrm{H}$ NMR spectrum of poly(4) (entry 12) obtained with $n-\mathrm{BuLi}$ in toluene and expanded spectra of the main chain methylene protons (a) and the polymer obtained with $\mathrm{Ph}_{2} \mathrm{NLi}$-TMEDA (entry 14$)$ (b) $\left(\mathrm{CDCl}_{3}, 60^{\circ} \mathrm{C}\right.$ ).

Each peak is sharp and assigned to poly(4) as shown in the figure, although small shoulder peaks appear probably due to a low $M_{n}$. The spectral pattern of the main chain methylene protons around $2.5 \mathrm{ppm}$ shows a typical $\mathrm{AB}$ quartet, indicating that the polymerization of $\mathbf{4}$ with $n$-BuLi in toluene proceeds in an isotactic-specific manner. Sharp singlets with the same chemical shift are observed in the ${ }^{13} \mathrm{C}$ NMR analysis of the carbonyl carbon of the polymers provided with $n$-BuLi in toluene and THF (entries 13 and 15) (Figures 6a and 6c). ${ }^{11}$ Highly isotactic polymers are surely produced regardless of the polarity of solvents. However, the polymer prepared using the complex of $\mathrm{Ph}_{2} \mathrm{NLi}^{-\mathrm{TMEDA}}$ (entry 14) shows much lower stereoregularity than those of poly $(4)$ s obtained with $n$-BuLi (Figure 6b). The ${ }^{1} \mathrm{H}$ NMR spectrum of the main chain methylene protons of this polymer also shows a quite different pattern from that of the highly isotactic polymer and should be rich in syndiotacticity (Figure 5b). A basic diamine ligand may prevent the coordination of polar substituents of the growing polymer and 4 with the counter-cation $\left(\mathrm{Li}^{+}\right)$, in addition to the less stable seven-membered chelation of intermediate lithium enolate which may play an important part in the stereocontrol.<smiles>CCCC1=C(OCC)ON2C=CC=CC2C1</smiles>

The thermal properties of novel stereoregular polymers were measured by DSC analysis. $T_{\mathrm{g}}$ were estimated to be 62,46 , and $81^{\circ} \mathrm{C}$ for poly $(3)$ s obtained with $n$ BuLi in toluene (entry 9), with $\mathrm{Ph}_{2} \mathrm{NLi}$-TMEDA (entry 10) and poly(1) prepared with lithium piperidide (entry 4), respectively, from the third heating thermograms. Both stereoregularity and heteroatoms of aromatic heterocycles in the monomers influence the thermal properties of the polymers.

In conclusion, $\mathbf{1}$ and three novel $\alpha$-substituted acrylates bearing aromatic heterocycles, $2-4$, were anionically polymerized to provide the corresponding vinyl polymers. The bulkiness and coordination ability of the polar substituents, aromatic heterocycles, of the growing polymer

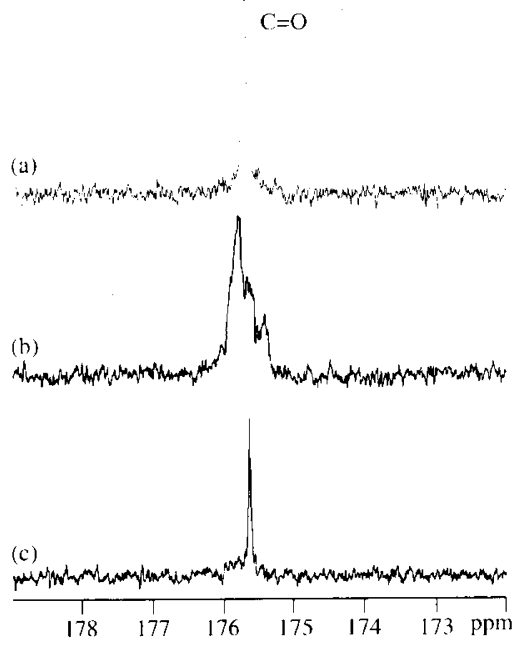

Figure 6. $100 \mathrm{MHz}{ }^{13} \mathrm{C} \mathrm{NMR}$ spectra of the carbonyl carbon in poly (4) s obtained with $n$-BuLi in toluene (entry 13) (a), $\mathrm{Ph}_{2} \mathrm{NLi}-$ TMEDA (entry 14) (b) and $n$-BuLi in THF (entry 15) (c) $\left(\mathrm{CDCl}_{3}, 60\right.$ $\left.{ }^{\circ} \mathrm{C}\right)$.

and monomers to the counter-cation $\left(\mathrm{Li}^{+}\right.$and $\mathrm{MgBr}^{+}$) greatly affected the stereoregularity of the polymers as well as polymerizability. The less stable seven-membered chelation of intermediate lithium enolate should have lower stereocontrol power than that of the stable sixmembered chelation in the anionic polymerization of $\alpha$ substituted acrylates. New functional polymers with thiophene, furan, and pyridine groups arranged on the main chain of a highly isotactic polyacrylate were synthesized.

Acknowledgment. This work was partially supported by a Grant-in-Aid for Scientific Research (No. 11450355) from the Ministry of Education, Science, Sports and Culture of Japan, and by CREST (Core Research for Evolutional Science and Technology) of Japan Science and Technology Corporation (JST).

\section{REFERENCES AND NOTES}

1. (a) S. Habaue, H. Yamada, and Y. Okamoto, Macromolecules, 29, 3326 (1996). (b) S. Habaue, H. Yamada, T. Uno, and Y. Okamoto, J. Polym. Sci., Part A: Polym. Chem., 35, 721 (1997). (c) T. Uno, S. Habaue, and Y. Okamoto, Chirality, 10, 711 (1998).

2. (a) S. Habaue, T. Uno, and Y. Okamoto, Macromolecules, 30, 3125 (1997). (b) S. Habaue, H. Baraki, and Y. Okamoto, Polym. J., 29, 872 (1997). (c) S. Habaue, T. Uno, H. Baraki, and Y. Okamoto, Polym. J., 29, 983 (1997).

3. S. Habaue, T. Shibagaki, and Y. Okamoto, Polym. J., 31, 942 (1999).

4. (a) H. Yuki and K. Hatada, Adv. Polym. Sci., 31, 1 (1979). (b) H. Yuki, K. Hatada, T. Niinomi, and K. Miyaji, Polym. J., 1, 130 (1970). (c) K. Hatada, S. Kokan, T. Niinomi, K. Miyaji, and H. Yuki, J. Polym. Sci., Polym. Chem. Ed., 13, 2117 (1975).

5. (a) H. Yuki, K. Hatada, T. Niinomi, M. Hashimoto, and J. Ohshima, Polym. J., 2, 629 (1971). (b) K. Hatada, J. Ohshima, T. Komatsu, S. Kokan, and H. Yuki, Polymer, 14, 565 (1973). (c) H. Yuki, K. Ohta, K. Hatada, and H. Ishikawa, Polym. J., 11, 323 (1979).

6. (a) R. W. Lenz, K. Saunders, T. Balakrishnan, and K. Hatada, Macromolecules, 12, 392 (1979). (b) T. Balakrishnan, R. Devarajan, and M. Santappa, J. Polym. Sci., Poly. Chem. Ed., 22, 1909 (1984). 
7. (a) E. L. Madruga, J. S. Román, M. A. Lavia, and M. C. F. Monreal, Macromolecules, 17, 989 (1984). (b) J. S. Román, E. L. Madruga, and M. A. Lavia, Macromolecules, 17, 1762 (1984). (c) J. S. Román, E. L. Madruga, and M. A. Lavia, Macromolecules, 19, 565 (1986). (d) E. L. Madruga, J. S. Román, and J. Alcalde, J. Polym. Sci., Part A: Polym. Chem., 26, 2281 (1988).

8. (a) Y. Wei, R. Hariharan, and R. Bakthavatchalam, J. Chem. Soc., Chem. Commun., 1160 (1993). (b) L. Gargallo, M. I. Muñoz, and D. Radic, Polymer, 27, 1416 (1986). (c) D. L. Trumbo, Polym. Bull., 36, 181 and 463 (1996). (d) M. E. Randazzo, L.
Toppare, and J. E. Fernandes, Macromolecules, 27, 5102 (1994). (e) D. L. Trumbo, F. T. Lin, F. M. Lin, and H. J. Harwood, Polym. Bull., 28, 87 (1992).

9. J. Villieras and M. Rambaud, Synthesis, 924 (1982).

10. There was no methanol insoluble part. The hexane insoluble polymer was collected after extraction with $\mathrm{CHCl}_{3}-\mathrm{H}_{2} \mathrm{O}$ system.

11. The reason why the signal of poly(4) prepared with $n$-BuLi in THF is narrower than that of the polymer obtained in toluene is not clear. 